\title{
Green Supplier Selection Based on Customer Needs Using Markov Chain and MCDM Method
}

\author{
ELBETTIOUI Wissal ${ }^{1}$, SBIHI Mohammed ${ }^{2}$, ZAIM Mounia ${ }^{2}$ \\ ${ }^{1}$ Mohammadia School of Engineers, Mohammed V University in Rabat Morocco, \\ Wissal.bettioui@gmail.com \\ ${ }^{2}$ University Mohammed V-Agdal, Superior School of Technology Sale, Sale, Morocco,
}

Received Date : October 05, 2021 Accepted Date : October 25, 2021 Published Date : November 07, 2021

\section{LITERATURE REVIEW}

\begin{abstract}
Supplier selection is a problem that has been widely discussed and addressed from different angles, but few works address the supplier selection problem by considering the needs of customers. After a literature review of the studies done on this topic none of them considered the changing desires and behavior of customers when evaluating green suppliers. This contribution then, will aim to design a green supplier selection model based on customer need using a recent MCDM decision making method and the Markov chain. The Markov chain is used to model and track changes in customer preferences and find a transition model. Then the (BWM) method is used to select the best ecological supplier.
\end{abstract}

Key words: Green supplier selection, MCDM methods, Best Worst Method, Markov chain.

\section{INTRODUCTION}

This Environmental concerns are now at the heart of all political, economic and social debates. Thus, the environment, which was not previously a major concern, is now attracting more and more interest from company managers. This manager, whose main objective is to maximize profit and improve the economic performance of his company, is now required to demonstrate a sense of responsibility [1]. The leader of today must give more importance to the integration of the environment in his strategic decisions. The integration of green practices in supply chain management is now a major criterion for improving the value of a brand in the marketplace, allowing the company to differentiate itself from its competitors [2]. This objective can be achieved by improving the supply chain and adopting new practices that have less impact on the environment. It is from this logic that the concept of green supply chain (GSCM) has emerged.

\subsection{Green Supply Chain Management}

Green Supply Chain Management or GSCM is a new concept that emerged after the deterioration of the environment and aims to make supply chains more environmentally friendly. There are several definitions of GSCM in the literature. Among the first works that defined GSCM are the researchers $\mathrm{Wu}, \mathrm{H}$. and Dunn, S.C [3] who mentioned that green logistics is a concept that aims to reduce environmental pollution, eliminate waste and save resource consumption and is not limited to reverse logistics [3]. In 2001 J. Sarkis and D. G. Dhavale [4] state that GSCM is based on the integration of environmental concerns into inter-organizational supply chain management practices. In 2006 Vachon and Klassen [5] defined GSCM as a set of environmental practices that encourage the improvement of environmental practices of two or more organizations within the same supply chain. According to Klassen and Johnson [6], there are five methods of green supply chain management; environmental certification, pollution prevention, reverse logistics, life cycle assessment, and eco-design [6]. The most popular and widely used definition in the literature comes from Srivastava [7], who defines GSCM as "the integration of environmental awareness into supply chain management, including product design, materials sourcing and selection, manufacturing processes, delivery of the final product to consumers, as well as the management of the product's end-of-life after its useful life" [7].

\subsection{Green Supplier Selection}

Given that the supplier selection process is of paramount importance in supply chain management. It is essential to integrate green practices for a transition to the design of a green supply chain increasingly respecting the environment [8]. Previously, the choice of suppliers was made instinctively, with the decision-maker relying mainly on the classic golden triangle criteria (cost, quality and delivery time) or on his own preferences. Faced with an increasingly demanding customer and heightened environmental awareness, the decision-maker is forced to reconsider his purchasing strategies and opt for new selection models that integrate the environmental aspect. 
According to our bibliography, the works dealing with the problem of supplier selection are multiple. We can trace the first publications since the 1960s. Dickson [9] is one of the first researchers to deal with the supplier selection problem. He examined a set of 23 criteria that researchers have or used after in their work. In the last decade the heights are increasingly interested in the environmental side in the selection of suppliers. Considering the environmental side of suppliers complicates the management of the purchasing process. Indeed, green procurement must take into account the environmental responsibility of the supplier, in addition to traditional factors such as supplier cost, quality, lead time and flexibility.

\subsection{The importance of Customer Needs}

Suppliers play a crucial role in the product manufacturing process and directly and indirectly influence the quality of the final product, namely quality is defined as what consumers want. On the other hand, customer satisfaction is highly dependent on the quality of the final products [10]. Research looking at analysis and decision making regarding customer needs is becoming increasingly important [11]. Researcher Asadabadi [12] is the first author to introduce a customer-oriented supplier selection method. He considered the customer's need as a determining factor in the search for the best supplier. For this purpose, he used a method integrating the analytical network process (ANP), quality function deployment (QFD) and a Markov chain. Yadavalli [13] adopted a modified version of the TOPSIS method using Z-numbers to select suppliers based on customer expectations, and developed a bi-objective mathematical model to allocate optimal amounts to the best performing suppliers. Yazdani et al., [11] considered customers' attitudes in the process of green provider selection and applied Stepwise Weighted Assessment Ratio Analysis (SWARA), QFD method, and Weighted Aggregate Product Sum Assessment (WASPAS) to select the optimal green provider. Falak Nawaz [14] developed a cloud broker architecture for cloud service selection by finding a model of changing priorities of user preferences using Markov chain and BWM decision making method.

\section{Problem description}

. In an increasingly competitive environment and faced with more and more demanding customers, companies are exposed to a diversity in the choice of the appropriate supplier meeting their criteria and satisfying their customers' desires. This selection is even more complicated when customers change their preferences according to their needs and the level of satisfaction with the service experienced or the product purchased. The objective of this paper is to overcome this drawback and develop a model for selecting the best green supplier by finding a model of the changing priorities of customer preferences. To solve this problem a Markov chain will be used to model, capture and track changes in customer preferences and find transition patterns, then the method (BWM), which is a multi-criteria decision making method
(MCDM), is used to rank the green suppliers.

\section{PROPOSED MODEL}

For solving the problem of ecological supplier selection based on classical and ecological selection criteria and customer need, and to overcome the problem of frequent change in customer desires and preferences we propose a model that uses a Markov chain in conjunction with the BWM method. The Markov chain is applied to trace and track the change in customer preferences and generate a model of these priorities. This model will then be used as input for the BWM method to be taken into consideration when comparing selection criteria. This method will allow us to rank the suppliers and choose the most appropriate one.

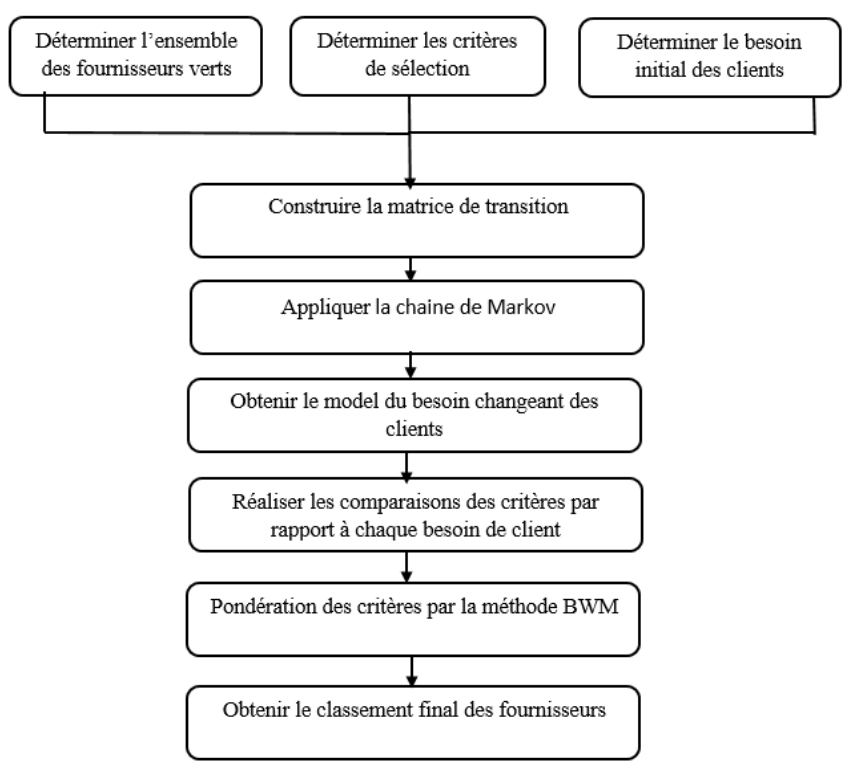

Figure.1: flowchart of the proposed model

\subsection{Data collection}

This step consists of determining the list of ecological selection criteria, the suppliers to be evaluated and the list of initial preferences of the clients. These preferences cannot be considered stable because they can change over time. We then build the transition matrix of the customers' preferences. The following figure allows us to better understand the transition phenomenon. It represents the passage from one state to another during the period $\mathrm{k}$.

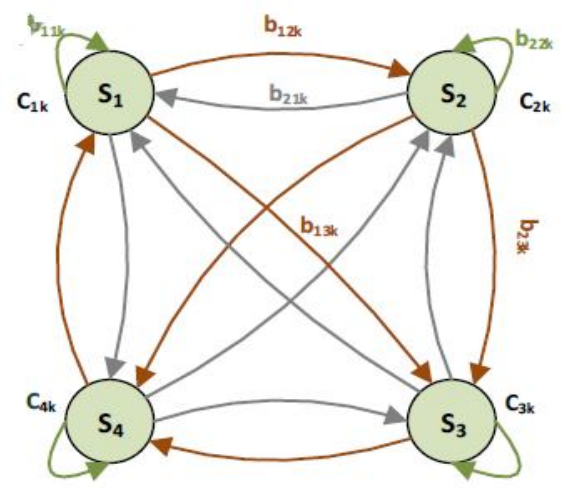

Figure 2: transitioning between states at $\mathrm{k}^{\text {th }}$ period 
To calculate the transition matrix, we calculate the probability of transition from a state $S_{\mathrm{i}}$ to another state $S_{\mathrm{j}}$ during the period $\mathrm{k}$ according to the following equation:

$$
\gamma_{i j k}=\frac{b_{i j k}}{c_{i k}}
$$

\section{2. application of Markov Chain}

The stabilized model of the changing needs of the customers is obtained by y frequently multiplying the transposition of the initial preference matrix by the transition matrix we obtain a set of $w_{\mathrm{r} r}^{(k)}$, where $\mathrm{k}$ is the number of multiplications Then we can determine the limit matrix of $\mathrm{P}$ denoted

$$
w_{C N}-p * w_{E}^{(k)}
$$

Given the convergence of stochastic matrices, we expect the matrices to become identical after three to five multiplications. The line of the limit matrix is considered as the Markov model of preference change.

\subsection{Green supplier selection using BWM}

Having found the pattern of change in customer desires we now apply the BWM method to find the relationship between customer preferences and criteria and weight the latter. Each criterion is compared to each customer preference, resulting in a matrix in which the rows represent the preferences and the columns the criteria.

Here we describe the supplier evaluation process using BWM method according to Falak Nawaz [14] :

1. Select a preference to find its relation with all the criteria

2. Determine the best and worst criteria with respect to the selected customer's need.

3. Determine the preference of the best criterion over all other criteria using a number between 1 and 9 , with 1 being the best preference and 9 being the worst. The same thing will be done for the worst criterion

5. finally we will find the optimal weights of the criteria (w1, w2, ..., wn).

These weights are obtained by solving the following problem:

$$
\left.\begin{array}{c}
\left|\frac{w_{B}}{w_{j}}-a_{B j}\right| \leq \xi \text {, for all } j \\
\left|\frac{w_{j}}{w_{w}}-a_{j w}\right| \leq \xi \text {, for all } j \\
\sum_{j} w_{j}=1 \\
\mathrm{~W}_{j} \geq 0, \text { for all } j
\end{array}\right\}
$$

Where the aij are the numbers between 1 and 9 that are assigned to the criteria (during the comparisons between the criteria) to express their preference over the best and worst criteria

So the criteria are compared with respect to each customer need. Each time, a set of weights of the criteria is calculated, these weights will build the rows of the comparison matrix.
6. Final weighting:

A matrix is determined by the result of the product of the previously calculated comparison matrix and the customer need priority model generated by the Markov chain

7. Final ranking of suppliers:

First, the evaluation matrix is constructed, which expresses the comparison of suppliers against the selection criteria according to the experts' opinion. Then we normalize this matrix according to the following equation:

$$
n_{i j}=\frac{r_{i j}}{\sum_{i=1}^{m} r_{i j}}
$$

The final ranking of the suppliers is obtained by the product of this normalized evaluation matrix and the transposed matrix calculated in step (6) containing the final weight of the selection criteria.

\section{CASE STUDY}

In order to test the efficiency of our proposed model in reality, a case study will be carried out in a Moroccan ceramic manufacturing company located in Berrechid region. For confidentiality reasons, the identity of the company will not be declared; instead, we refer to the company as $\mathrm{ABC}$ and its potential three green suppliers GS1, GS2, and GS3. in this study the following list of customer needs and set of criteria will be considered:

- Set of customer needs: (Safety, Hygiene, Shape, Surface Appearance)

- Set of criteria (cost, quality, environment management system, pollution control, Green product)

\section{A. Data collection}

We conducted a questionnaire survey among the customers of the company $\mathrm{X}$ leader in its field. This survey allows us to observe the behavior of the customers while purchasing the product. The survey was conducted in two stages, the first one being to determine the initial preferences of the customers and the second one to detect the change in their preferences. We worked on a sample of 25 customers. The survey was distributed to our target audience directly after the act of purchase so that they have a clear idea of their needs. The customer is asked to fill in the questionnaire during his next order, after a period of 4 weeks. After examining and interpreting the responses to the distributed questionnaires, the transition matrix is constructed as follows:

\section{B. Application of Markov Chain}

Thanks to the application of the Markov chain, the changing needs of the customers will stabilize after several multiplications and independently of the initial needs in the following vector:

$$
W_{C N}=p * w_{k}^{(k)}
$$

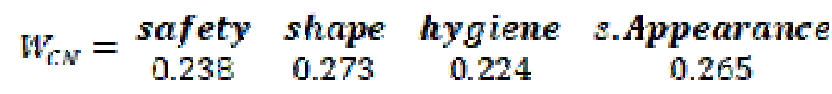


this final matrix, the result of this application will be used as input for the BWM method.

\section{Green Supplier Selection Using BWM}

criteria comparison with respect to each Customer Need is done using the procedure described in section 4.3

The result of the criteria evaluation considering the customer's needs is represented in the following matrix.

$\begin{array}{ccccccc} & \text { cost } & \text { quality } & \text { EMS } & \text { p.control } & \text { Gr.product } \\ w_{C N-c r}-\quad \text { safety } & 0.044 & 0.321 & 0.139 & 0.411 & 0.083 \\ \text { shape } & 0.220 & 0.494 & 0.056 & 0.005 & 0.066 \\ \text { hygiene } & 0.06 & 0.495 & 0.137 & 0.22 & 0.076 \\ \text { s.appearance } & 0.09 & 0.516 & 0.116 & 0.204 & 0.072\end{array}$

the final weight of the criteria is obtained by multiplying the transpose of the customer needs priority vector with the criteria -Customer Need comparison matrix:

$$
\begin{aligned}
& \boldsymbol{w}_{c r}=w_{C N-c r} * w_{C N} \\
& w_{c r}=\begin{array}{ccccc}
\text { cost } & \text { quality } & \text { EMS } & \text { P.control } & \text { Gr.product } \\
0.11 & 0.458 & 0.109 & 0.224 & 0.073
\end{array}
\end{aligned}
$$

The following matrix shows the analysis of the expert data regarding the evaluation of the three potential suppliers

\begin{tabular}{|c|c|c|c|c|c|}
\hline & Cost & quality & EMS & P.control & Gr.product \\
\hline$=G S 1$ & 0.323 & 0.534 & 0.41 & 0.224 & 0.287 \\
\hline GS2 & 0.421 & 0.144 & 0.22 & 0.286 & 0.167 \\
\hline GS3 & 0.256 & 0.089 & 0.37 & 0.49 & 0.546 \\
\hline
\end{tabular}
against each criterion

the final weight of each supplier is obtained by multiplying the criteria evaluation matrix and the criteria weight matrix

$\begin{array}{ll}\text { GS1 } & 0.39 \\ \text { GS2 } & 0.22 \\ \text { GS3 } & 0.25\end{array}$

\section{RESULTS AND DISCUSSION}

In this study three suppliers were evaluated according to both green and traditional criteria while considering the customers' needs. Potential suppliers and selection criteria were suggested and selected by a group of experts from the company under study. The Markov chain was applied to capture the change in customer preferences and the BWM method is used to weight the criteria and select the best performing supplier considering the customer's need. The result of this model ranked Quality in first position followed by pollution control and cost. These results show that decision makers should no longer be satisfied with judging their suppliers according to the traditional golden triangle criteria (cost, quality, delivery time) but also that ecological criteria are now important criteria that must be integrated into their purchasing process. GS1, even if he is not very efficient in terms of cost criteria, is ranked in first position as being the first choice of the decision makers. This supplier may be a little overpriced compared to its competitors, but its products are of the highest quality. An intuitive decision that does not take into account the customer's needs will lean towards the supplier that offers reasonable prices and a moderately acceptable quality. GS2, even though he offers a better price and quality than GS3, he was at the bottom of the ranking. GS3 won its place thanks to its environmental performance. $\mathrm{He}$ is the best performing supplier in terms of environmental criteria. Our model shows that a good understanding of the customer's needs allows to improve the results of the suppliers' evaluation and to guarantee the satisfaction of its customers.

\section{CONCLUSION}

In recent years, the green supplier selection problem has been widely addressed by researchers using several decision-making methods. However, considering the changing needs of customers in this decision making requires more attention from researchers. As highlighted by the author, a good cooperation with the different partners is now one of the main methods of the supply chain [15]. The result of this work is an innovative model of green supplier selection based on customer need. This model uses Markov chain to track and capture the change in customer preferences and a recent BWM decision making method (MCDM) to weight the selection criteria and rank the green suppliers.

\section{REFERENCES}

1. P. Žukauskas, J. Vveinhardt and R. Andriukaitienè (2018) Corporate Social Responsibility as the Organization's Commitment against Stakeholders DOI: $10.5772 /$ intechopen. 70625

2. Chin, Thoo \& Sulaiman, Zuraidah \& Huam, Tat \& Zainon, Siti. (2015). Green Supply Chain Management Practices and Sustainability Performance. Advanced Science Letters. 21. 10.1166/asl.2015.6029.

3. Wu, H. and Dunn, S.C. (1995), Environmentally responsible logistics systems, International Journal of Physical Distribution \& Logistics Management, Vol. 25 No. 2, pp. 20-38.

4. J. Sarkis and D. G. Dhavale. Supplier selection for sustainable operations: a triple-bottom-line approach using a Bayesian framework, International Journal of Production Economics 2001

5. Vachon Stephan \& Klassen Robert. (2006). Extending Green Practices Across the Supply Chain: The Impact of Upstream and Downstream Integration. International Journal of Operations \& Production Management. $26 . \quad 795-821$. 10.1108/01443570610672248.

6. Klassen R., Johnson, P.F. (2004), The green supply chain. In Westbrook, R. \& New, S. (Eds.). Under-standing Supply Chains - Concepts, Critiques and Futures. pp. $229-251$ 
7. Srivastava, Samir. (2007). Green Supply Chain Management: A State-of-The-Art Literature Review. International Journal of Management Reviews. 9. 53 80. 10.1111/j.1468-2370.2007.00202x.

8. Burki Umar. (2018). Green Supply Chain Management, Green Innovations, and Green Practices. Innovative Solutions for Sustainable Supply Chains (pp.81-109) 10.1007/978-3-319-94322-0_4.

9. Dickson G. W. (1966). An analysis of vendor selection: systems and decisions. Journal of Purchasing, vol. 2( 1), pp. 5-17.

10. Goetsch, D.L. and Davis, S.B. (2014) Quality Management for Organizational Excellence.

11. Yazdani, M., Chatterjee, P., Zavadskas, E. K., \& Zolfani, S. H. (2017). Integrated QFD-MCDM framework for green supplier selection. Journal of Cleaner Production, 142, 3728-3740.

12. Mehdi Rajabi Asadabadi (2017) A customer based supplier selection process that combines quality function deployment, the analytic network process and a Markov chain. European Journal of Operational Research

13. V. S. Yadavalli, J. D. Darbari, N. Bhayana, P. C. Jha, and V. Agarwal (2019) An integrated optimization model for selection of sustainable suppliers based on customers' expectations. Operations Research Perspectives, vol. 6, Article ID 100113

14. Falak Nawaz, M.R. Asadabadi, N.J. Janjua, O.K. Hussain, E.Chang, M. Saberi Cloud Service Selection Using a Markov Chain and the Best-Worst Method, Knowledge-Based Systems, 2018 doi: 10.1016/j.knosys.2018.06.010

15. D. S. N. Raghavarapu and D. K.-J. Meier, "Methodology for Supply Chain Management," International Journal of Emerging Technologies in Engineering Research (IJETER), vol. 4, no. 10, 2016 